\title{
Molecular targeted therapies of renal cell carcinoma considering life stage of the patient: Two case reports
}

\author{
HISASHI TAKEUCHI, NAOTO TOKUYAMA, ISAO KURODA and TEIICHIRO AOYAGI \\ Department of Urology, Tokyo Medical University Ibaraki Medical Center, Inashiki, Ibaraki 300-0395, Japan
}

Received November 11, 2016; Accepted March 3, 2017

DOI: $10.3892 /$ etm.2018.5882

\begin{abstract}
Molecular targeted therapies have markedly improved the prognosis of metastatic renal cell carcinoma (RCC) and patients are able to receive specific treatments depending on their condition. The cases of two patients who presented with large RCC with very different statuses were examined in the current study. One of the patients was elderly with numerous comorbidities, and the other was young and had Case 1 was an elderly female with various comorbidities including a history of cerebral infarction and impaired eyesight. A $7 \mathrm{~cm}$ solid mass in the left kidney, pulmonary metastases and a shrunken right kidney were identified. Conservative treatment was selected and the patient underwent treatment with oral sorafenib for 5 years without experiencing disease progression. Case 2 was a middle-aged male in a good general condition who had a $19 \mathrm{~cm}$ left renal mass and multiple metastases. Due to the tumor size, the patient was initially treated with oral pazopanib to reduce the renal tumor volume and was able to undergo left radical nephrectomy after 6 months. Molecular targeted therapies were thus used to treat these patients taking into account each patient's life stage; case 1 was treated without surgery for six years and case 2 received treatment as a neoadjuvant.
\end{abstract}

\section{Introduction}

Each year, 338,000 patients are newly diagnosed with kidney cancer worldwide (1). Renal cell carcinoma (RCC) accounts for $3 \%$ of all adult malignancies and $90 \%$ of neoplasms arising from the kidney (2). Of patients with initially localized disease who undergo nephrectomy, 20-40\% develop metastases (3). Patients with metastatic disease have a poor prognosis, with 5 -year survival rates $<10 \%$ (3). Molecular targeted therapies have markedly improved the prognosis of patients with

Correspondence to: Dr Hisashi Takeuchi, Department of Urology, Tokyo Medical University Ibaraki Medical Center, 3-20-1, Chuo, Ami-machi, Inashiki, Ibaraki 300-0395, Japan

E-mail: hisashi917@yahoo.co.jp

Key words: renal cell carcinoma, molecular targeted therapies, cytoreductive nephrectomy, sorafenib, pazopanib metastatic RCC. In metastatic renal cell carcinoma (mRCC) the tyrosine-kinase inhibitor sunitinib leads to progression-free survival (PFS) of 11.5 months and an overall survival (OS) of 26 months, which may reach 40 months with adequate sequential therapy (4-7). Patients are now able to receive different treatments, including surgery, molecular target therapies and immunotherapies depending on their age and past history.

In Japan, four types of tyrosine kinase inhibitors (TKIs), sorafenib, sunitinib, axitinib and pazopanib; and two types of mammalian targets of rapamycin (mTOR) everolimus and temsirolimus are available for patients with metastatic RCC as a first-line molecular targeted therapy. However, physicians are currently required to select the appropriate treatment for each patient based on the stage of cancer and age of the patient etc.

In the present study, the cases of two patients with metastatic RCC from very different backgrounds and at very different life stages were examined. Both patients provided written informed consent for inclusion in the study.

\section{Case report}

Case 1. The first patient was an 80-year-old Japanese female who had been diagnosed with a left $7 \mathrm{~cm}$ renal mass and was referred to Tokyo Medical University Ibaraki Medical Center (Ibaraki, Japan) in June, 2011. The patient had a history of cerebral infarction and impaired eyesight. Laboratory findings were as follows: Hemoglobin ( $\mathrm{Hb}$ ), $13.8 \mathrm{~g} / \mathrm{ml}$ (normal range, 12 16 g/ml); hematocrit (Ht), 40.4\% (normal range, 34 42\%); leukocytes, 4,600 cells/ml (normal range, 4,000 9,000 cells $/ \mathrm{ml}$ ); blood urea nitrogen (BUN), $8.4 \mathrm{mg} / \mathrm{dl}$ (normal range, $8 \sim 23 \mathrm{mg} / \mathrm{dl}$ ); and creatinine $(\mathrm{Cr}), 0.98 \mathrm{mg} / \mathrm{dl}$ (normal range, $0.6 \sim 1.2 \mathrm{mg} / \mathrm{dl}$ ). Urinalysis indicated $0-1$ (normal range, $<5$ ) white and 0-1 (normal range, <5) red blood cells per high-power field.

Computed tomography (CT) scan and magnetic resonance imaging (MRI) revealed a solid mass of $\sim 7 \mathrm{~cm}$ in the left kidney with small pulmonary metastases and indicated that the patient's right kidney was atrophic (Figs. 1 and 2). This renal tumor was hypervascular and suggestive of RCC.

Following consultation with the patient and family regarding the treatment, conservative treatment was selected, as the patient would have required dialysis, due to having a right atrophic kidney, if a left radical nephrectomy was performed. Furthermore, the patient was already wheelchair bound, due to impaired eyesight and brain infarction. 
Therefore, the patient began treatment with oral sorafenib (Bayer, Leverkusen, Germany) at $200 \mathrm{mg} / \mathrm{day}$. With a prominent rise in the blood levels of creatine phosphokinase (CPK) up to 452 IU (normal range, 32 187 IU), the dose of oral sorafenib was reduced to $200 \mathrm{mg}$ every 2 days. This dose was well tolerated by the patient without adverse events.

Disease progression was observed on a follow-up CT scan every 6 months for 5 years, which demonstrated that the left renal tumor and pulmonary metastases remained stable for first two years but they were slowly progressing and new pulmonary metastases had emerged after 2 years (Fig. 2). However, the patients' quality of life (QOL), including renal function, was well maintained up to 5 years following the initiation of sorafenib treatment. In addition, the patient has continued to use sorafenib on this schedule despite mid disease progression as no severe adverse events have occurred.

Case 2. The second patient was a 39-year-old Japanese male who had been diagnosed with a left $19 \mathrm{~cm}$ of renal mass and was referred to Tokyo Medical University Ibaraki Medical Center November, 2015. Laboratory findings were as follows: $\mathrm{Hb}, 13.6 \mathrm{~g} / \mathrm{ml}$ (normal range, 14 17 g/ml); Ht, 41.8\% (normal range, 40 48\%); leukocytes, 6,500 cells/ml (normal range, 4,000 9,000 cells/ml); BUN, $12.7 \mathrm{mg} / \mathrm{dl}$ (normal range, $8 \sim 23 \mathrm{mg} / \mathrm{dl}$ ) ; and $\mathrm{Cr}, 1.01 \mathrm{mg} / \mathrm{dl}$ (normal range, $0.6 \sim 1.2 \mathrm{mg} / \mathrm{dl}$ ). Urinalysis indicated 10-19 (normal range, $<5$ ) white and $>100$ (normal range, $<5$ ) red blood cells per high-power field.

CT and MRI identified a solid mass, $\sim 19 \mathrm{~cm}$ in the left kidney with multiple pulmonary, hepatic and lymph node metastases and a long embolus in the left renal vein (Fig. 1A). This renal tumor was hypervascular and suggestive of RCC.

Due to the large size of the renal tumor, the patient began treatment with oral pazopanib (GlaxoSmithKline plc, London, $\mathrm{UK}$ ) at $800 \mathrm{mg} / \mathrm{day}$ to reduce the tumor volume. The pazopanib treatment was continued with only slight fatigue without major adverse effects.

Following 6 months from the initiation of pazopanib treatment, a CT scan indicated a $\sim 10 \%$ regression based on the Response Evaluation Criteria in Solid Tumors (8). In addition, the long embolus in the left renal vein was reduced, reaching from across the aortic atresia to the left side of aortic atresia (Fig. 3). A left radical nephrectomy was performed. The histology of the renal tumor indicated clear cell RCC, Fuhrman nuclear grade 2 (9), with features of papillary RCC and sarcomatoid carcinoma that was classified as pathological stage T3aN1M1 according to TMN classification (Fig. 4) (10). In addition, some areas exhibited necrosis. The patient has continued to use pazopanib at $800 \mathrm{mg} /$ day following left radical nephrectomy.

\section{Discussion}

With the introduction of molecular targeted therapy, treatment of metastatic RCC has improved markedly; previously, only immunotherapies, including interferon- $\alpha$ and $-\gamma$ or interleukin (IL)-2, were used to treat renal cancer (11). However, immunotherapies do not have a prominent effect on the response or survival of late stage RCC (11).

Molecular targeted therapy exhibits prominent effects in the treatment of RCC. However, the adverse effects, including general fatigue or myelosuppression are severe and the treatment often has to be discontinued (12-15). The continuity of molecular targeted therapy is important and further consideration of the prescription plan depending on the state of the patient and tumor status is required. In addition, it has been reported that there are differences in the clinical features of patients with RCC, for example elderly patients with RCC display significantly higher cancer-specific mortality and other-cause mortality rates in comparison with their younger counterparts (16). There is a possibility that treatment according to standard guidelines may not be suitable in every case.

In the present study, case 1 was an elderly patient with comorbidities. The patients' renal tumor exhibited slow progression; however, QOL was well maintained and the molecular targeted therapy was well tolerated without severe adverse events. Generally, in case of elderly patients, treatment is discontinued due to adverse events such as fatigue and loss of appetite; however, sorafenib induces fewer adverse effects than other TKIs and the use of sorafenib is recommended for such patients (17). In particular, sorafenib has little influence on the renal function, so it is better for older patients such as case 1 , enabling them to avoid further deterioration of kidney function (18). However, vascular endothelial growth factor inhibitors induce major adverse effects, including myelosuppression, cardiotoxicity, hypertension, thrombocytopenia, fatigue and loss of appetite (19). Therefore, patients with poor conditions should consider treatment with mTOR inhibitors such as everolimus and temsirolimus.

Sorafenib does not induce evident adverse events; however, the rate of continuation of sorafenib treatment $>1$ year is only $30 \%$ in Japan (20). To continue treatment, optimal adjustment dose or a prescription interval is required.

Nephrectomy was performed on case 2 following cytoreduction using pazopanib. In the cytokine therapy period (interferon and Il-2), nephrectomy to resect the primary tumor for patients with metastatic RCC is useful in improving the survival rate (cytoreductive nephrectomy) (21-23). A number of studies report that cytoreductive nephrectomy improves the survival rate in patients with metastatic RCC undergoing molecular targeted therapy $(24,25)$. However, the usefulness of molecular targeted therapy administered prior to surgery as neoadjuvant therapy for patients with metastatic RCC remains controversial (26-28). Setting an end point for neoadjuvant therapy is difficult and the timing of the surgery might be missing by the therapy if molecular targeted therapy dose not effect for RCC and tumor would be growing.

However, molecular targeted therapy is able to reducing the primary tumor size (19), therefore, there is a possibility that molecular targeted therapy administered prior to surgery may reduce the invasiveness of surgery for patients with local invasive RCC.

However, care must be taken prior to administering molecular targeted therapy prior to surgery to avoid adverse effects which may, in turn, influence surgical treatment.

Case 2 was a young patient with a high PS; thus, resection of the primary tumor by surgery was recommended. In this case, primary tumor resection was safely performed following a reduction of the primary tumor volume by administration of molecular targeted therapy, which did not induce any severe adverse effects. 
A

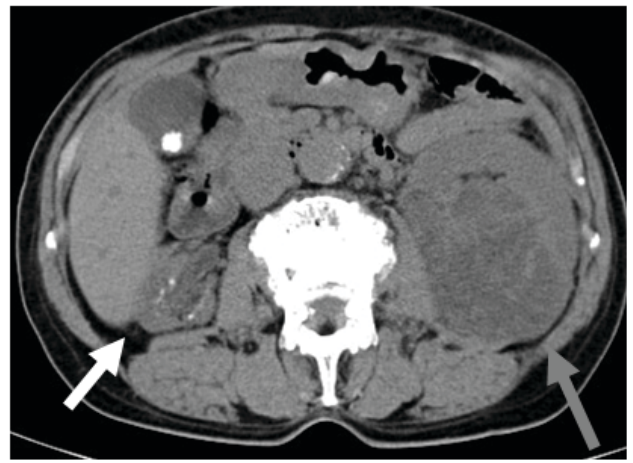

C

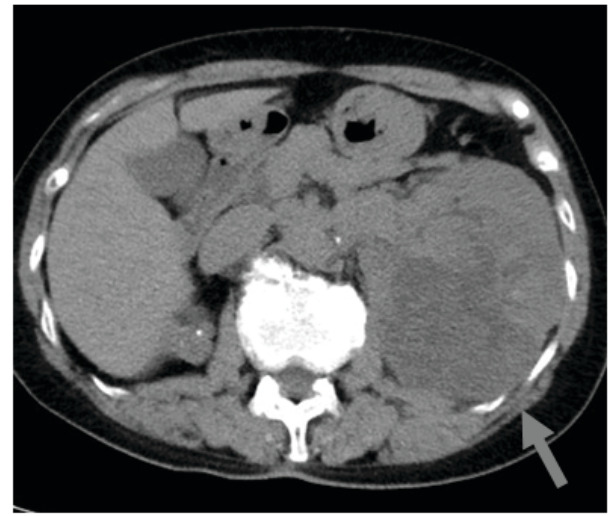

B

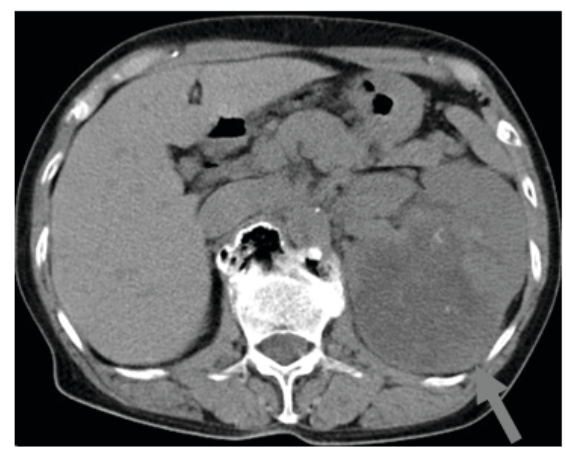

D

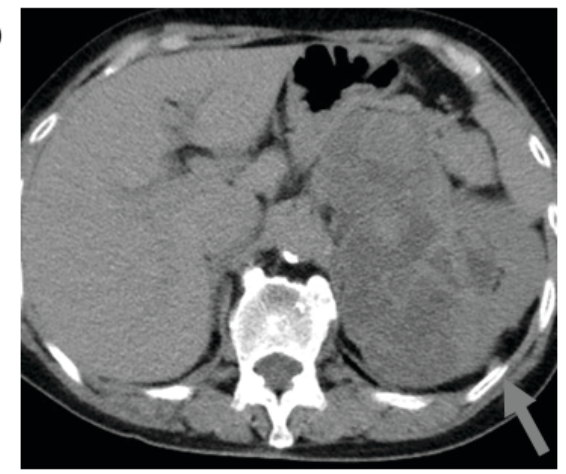

Figure 1. Abdominal CT scans of the patient in case 1 with metastatic renal cell carcinoma (gray arrows) at different time points. (A) CT scan prior to initiation of treatment with sorafenib indicates a solid mass of $\sim 7 \mathrm{~cm}$ in size in the left kidney (gray arrow) and a right atrophic kidney (white arrow). (B) CT scan 1 year following the initiation of sorafenib therapy. (C) CT scan 3 years after the initiation of sorafenib. (D) CT scan 5 years after the initiation of sorafenib. CT scans revealed that this tumor size was slowly increasing by $38.2 \%$ (gray arrow). CT, computed tomography.

A

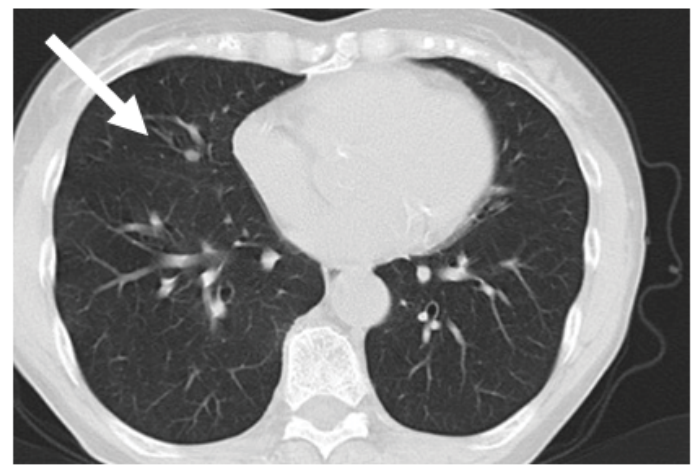

C

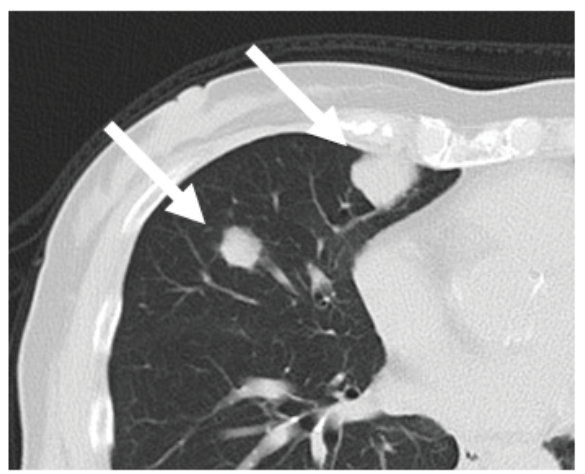

\section{B}

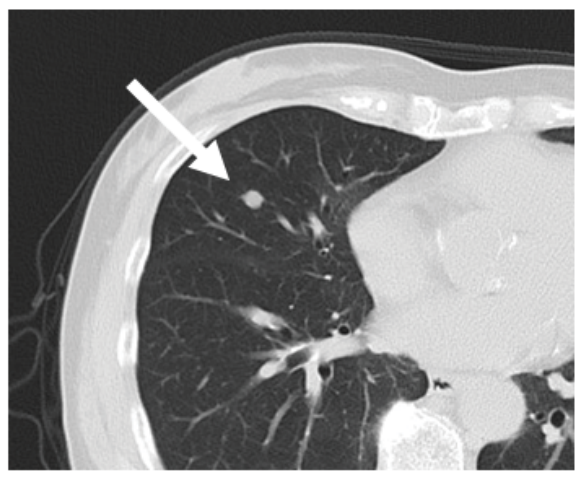

Figure 2. Chest CT scans of case 1 indicating metastases. (A) CT scan performed prior to the initiation of treatment with sorafenib revealed small pulmonary metastatic lesions (white arrow). (B) CT scan obtained 3 years following initiation of sorafenib treatment revealed tumor regression (white arrow). (C) CT scan obtained 5 years after the initiation of sorafenib revealed tumor regression and new pulmonary metastases (white arrow). CT, computed tomography. 

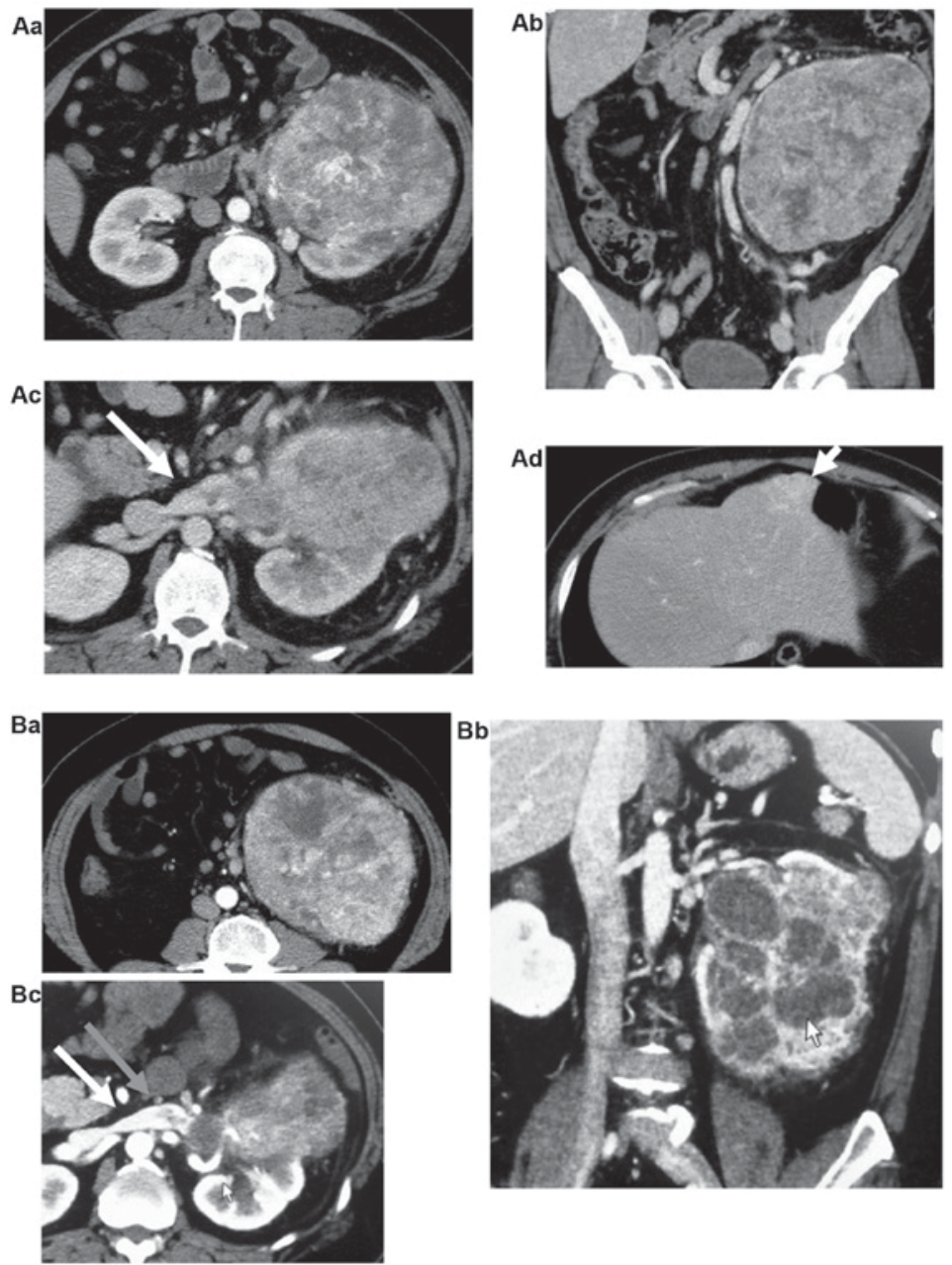

Figure 3. CT scans of Case 2 with metastatic renal cell carcinoma at different time points. CT scan indicated $\sim 10 \%$ regression in solid tumors. (A) CT scans prior to the initiation of treatment with pazopanib of the left kidney; (Aa) coronal, (Ab), sagittal, (Ac) embolus in the renal vein (white arrow) and (Ad) a round metastatic site identified in the liver (white arrow). (B) CT scan prior to radical nephrectomy of the left kidney (Ba) coronal, (Bb) sagittal, (Bc) level of embolus in the renal vein. White and gray arrows indicate embolus prior to and following treatment, respectively. CT, computed tomography.

A

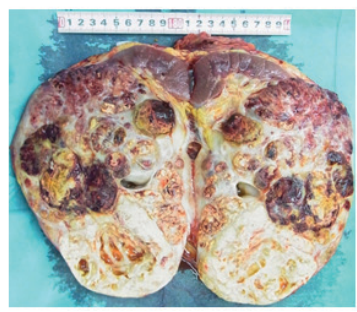

B

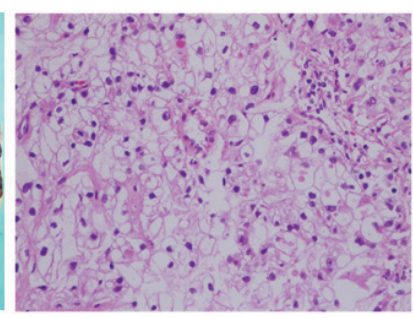

C

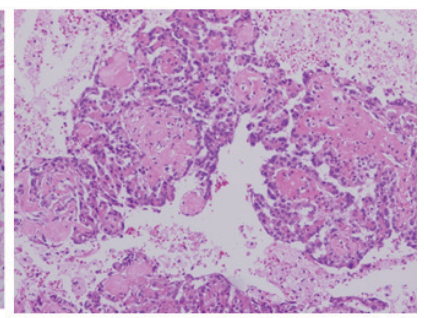

D

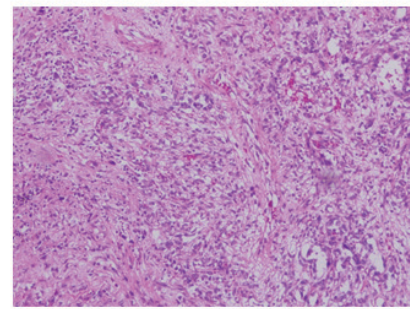

E

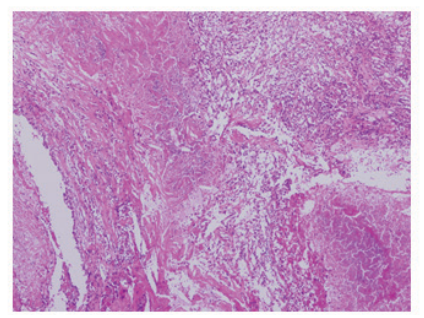

Figure 4. Gross and histopathological sections of the renal tumor in case 2. (A) Gross section of the specimen. Histopathological sections indicating (B) RCC of Fuhrman nuclear grade 2 (magnification, x40), (C) with the features of papillary RCC and (D) sarcomatoid carcinoma (C and D; magnification, x100). (E) Some necrosis was exhibited along with bleeding, fibrosis, mucous tumor-like change and cellular infiltration of phlogocyte due to the effects of pazopanib (magnification, x40). Hematoxylin-eosin stain was used. RCC, renal cell carcinoma. 
In conclusion, the present study examined the cases of two patients with metastatic RCC with very different backgrounds who were at different life stages. Case 1 was elderly and with a past medical history that included cerebral infarction, therefore the dose of sorafenib used for treatment was reduced. Case 2 was younger and exhibited enough PS, therefore surgical resection of the primary tumor was deemed desirable. The current study indicated that molecular targeted therapy is effective at reducing the tumor burden of RCC prior to radical nephrectomy. A number of different methods of molecular targeted therapy may be used, depending on the state of the patient and the tumor status. The current case report furthers understanding of the characteristics of molecular targeted therapy in the treatment of renal cell carcinoma.

\section{Competing interests}

The authors declare that they have no competing interests.

\section{References}

1. Ferlay J, Soerjomataram I, Dikshit R, Eser S, Mathers C, Rebelo M, Parkin DM, Forman D and Bray F: Cancer incidence and mortality worldwide: Sources, methods and major patterns in GLOBOCAN 2012. Int J Cancer 136: E359-E386, 2015.

2. Chow WH, Devesa SS, Warren JL and Fraumeni JF Jr: Rising incidence of renal cell cancer in the United States. JAMA 281: $1628-1631,1999$.

3. Fry DE, Amin M and Harbrecht PJ: Rectal obstruction secondary to carcinoma of the prostate. Ann Surgery 189: 488-492, 1979 Motzer RJ, Bander NH and Nanus DM: Renal-cell carcinoma. N Engl J Med 335: 865-875, 1996.

4. Escudier B, Eisen T, Stadler WM, Szczylik C, Oudard S, Siebels M, Negrier S, Chevreau C, Solska E, Desai AA, et al Sorafenib in advanced clear-cell renal-cell carcinoma. N Engl J Med 356: 125-134, 2007

5. Hudes G, Carducci M, Tomczak P, Dutcher J, Figlin R, Kapoor A, Staroslawska E, Sosman J, McDermott D, Bodrogi I, et al: Temsirolimus, interferon alfa, or both for advanced renal-cell carcinoma. N Engl J Med 356: 2271-2281, 2007.

6. Motzer RJ, Hutson TE, Tomczak P, Michaelson MD, Bukowski RM, Rixe O, Oudard S, Negrier S, Szczylik C, Kim ST, et al: Sunitinib versus interferon alfa in metastatic renal-cell carcinoma. N Engl J Med 356: 115-124, 2007.

7. Rini BI, Escudier B, Tomczak P, Kaprin A, Szczylik C, Hutson TE, Michaelson MD, Gorbunova VA, Gore ME, Rusakov IG, et al: Comparative effectiveness of axitinib versus sorafenib in advanced renal cell carcinoma (AXIS): A randomised phase 3 trial. Lancet 378: 1931-1939, 2011.

8. Eisenhauer EA, Therasse P, Bogaerts J, Schwartz LH, Sargent D, Ford R, Dancey J, Arbuck S, Gwyther S, Mooney M, et al: New response evaluation criteria in solid tumours: revised RECIST guideline (version 1.1). Eur J Cancer 45: 228-247, 2009.

9. Fuhrman SA, Lasky LC and Limas C: Prognostic signoficance of morphologic parameters in renal cell carcinoma. Am J Surg Pathol 6: 655-663, 1982.

10. Sobin LH, Gospodarowicz MK and Wittekind C, Ed.: TNM classification of malignant tumours, 7th Edition, Wiley-Blackwell, New Jersey, pp. 255-257, 2009.

11. Pantuck AJ,Zisman A and Belldegrun AS: The changing natural history of renal cell carcinoma. J Urol 166: 1611-1623, 2001.

12. Motzer RJ, Hutson TE, Tomczak P, Michaelson MD, Bukowski RM, Oudard S, Negrier S, Szczylik C, Pili R, Bjarnason GA, et al: Overall survival and updated results for sunitinib compared with interferon alfa in patients with metastatic renal cell carcinoma. J Clin Oncol 22: 3584-3590, 2009.

13. Faivre S, Delbaldo C, Vera K, Robert C, Lozahic S, Lassau N, Bello C, Deprimo S, Brega N, Massimini G, et al: Safety, pharmacokinetic, and antitumor activity of SU11248, a novel oral multitarget tyrosine kinase inhibitor, in patients with cancer. J Clin Oncol 1: 25-35, 2006.
14. Gore ME, Szczylik C, Porta C, Bracarda S, Bjarnason GA, Oudard S, Hariharan S, Lee SH, Haanen J, Castellano D, et al: Safety and efficacy of sunitinib for metastatic renal-cell carcinoma: An expanded-access trial. Lancet Oncol 8: 757-763, 2009.

15. Sternberg CN, Davis ID, Mardiak J, Szczylik C, Lee E, Wagstaff J, Barrios CH, Salman P, Gladkov OA, Kavina A, et al: Pazopanib in locally advanced or metastatic renal cell carcinoma: Results of a randomized phase III trial. J Clin Oncol 6: 1061-1068, 2010.

16. May M, Cindolo L, Zigeuner R, De Cobelli O, Rocco B, De Nunzio C, Tubaro A, Coman I, Truss M, Dalpiaz O, et al: Results of a comparative study analyzing octogenarians with renal cell carcinoma in a competing risk analysis with patients in the seventh decade of life. Urol Oncol 32: 1252-1258, 2014

17. Escudier B, Szczylik C, Hutson TE, Demkow T, Staehler M, Rolland F, Negrier S, Laferriere N, Scheuring UJ, Cella D, et al: Randomized phase II trial of first-line treatment with sorafenib versus interferon Alfa-2a in patients with metastatic renal cell carcinoma. J Clin Oncol 8: 1280-1289, 2009.

18. Zhang HL, Qin XJ, Wang HK, Gu WJ, Ma CG, Shi GH, Zhou LP and Ye DW: Clinicopathological and prognostic factors for long-term survival in Chinese patients with metastatic renal cell carcinoma treated with sorafenib: A single-center retrospective study. Oncotarget 6: 36870-36883, 2015.

19. Motzer RJ, Escudier B, Tomczak P, Hutson TE, Michaelson MD, Negrier S, Oudard S, Gore ME, Tarazi J, Hariharan S, et al: Axitinib versus sorafenib as second-line treatment for advanced renal cell carcinoma: Overall survival analysis and updated results from a randomised phase 3 trial. Lancet Oncol 14: $552-562,2013$

20. Akaza H, Naito S, Ueno N, Aoki K, Houzawa H, Pitman Lowenthal S and Lee SY: Real-world use of sunitinib in Japanese patients with advanced renal cell carcinoma: Efficacy, safety and biomarker analyses in 1689 consecutive patients. Jpn J Clin Oncol 45: 576-583, 2015.

21. Mickisch GH, Garin A, van Poppel H, de Prijck L and Sylvester R; European organisation for research and treatment of cancer (EORTC) genitourinary Group: Radical nephrectomy plus interferon-alfa-based immunotherapy compared with interferon alfa alone in metastatic renal-cell carcinoma: A randomised trial. Lancet 358: 966-970, 2001.

22. Flanigan RC, Salmon SE, Blumenstein BA, Bearman SI, Roy V, McGrath PC, Caton JR Jr, Munshi N and Crawford ED: Nephrectomy followed by interferon alfa-2b compared with interferon alfa-2b alone for metastatic renal-cell cancer. N Engl J Med 345: 1655-1659, 2001.

23. Flanigan RC, Mickisch G, Sylvester R, Tangen C, Van Poppel H and Crawford ED: Cytoreductive nephrectomy in patients with metastatic renal cancer: A combined analysis. J Urol 171: 1071-1076, 2004

24. Choueiri TK, Xie W, Kollmannsberger C, North S, Knox JJ, Lampard JG, McDermott DF, Rini BI and Heng DY: The impact of cytoreductive nephrectomy on survival of patients with metastatic renal cell carcinoma receiving vascular endothelial growth factor targeted therapy. J Urol 185: 60-66, 2011.

25. Heng DY, Xie W, Regan MM, Warren MA, Golshayan AR, Sahi C, Eigl BJ, Ruether JD, Cheng T, North S, et al: Prognostic factors for overall survival in patients with metastatic renal cell carcinoma treated with vascular endothelial growth factor-targeted agents: results from a large, multicenter study. J Clin Oncol 27: 5794-5799, 2009.

26. Wood CG and Margulis V: Neoadjuvant (presurgical) therapy for renal cell carcinoma: A new treatment paradigm for locally advanced and metastatic disease. Cancer 115 (10 Suppl): S2355-S2360, 2009.

27. Powles T, Blank C, Chowdhury S, Horenblas S, Peters J, Shamash J, Sarwar N, Boleti E, Sahdev A, O'Brien T, et al: The outcome of patients treated with sunitinib prior to planned nephrectomy in metastatic clear cell renal cancer. Eur Urol 60: 448-454, 2011.

28. Bex A, Blank C, Meinhardt W, van Tinteren H, Horenblas S and Haanen J: A phase II study of presurgical sunitinib in patients with metastatic clear-cell renal carcinoma and the primary tumor in situ. Urology 78: 832-837, 2011. 